“Transfer” XV: 1-2 (2020), pp. 412-433. ISSN: 1886-554

\title{
LA EVOLUCIÓN DE LA IMAGEN DE LA MUJER EN EL CÓMIC ITALIANO Y SU RECEPCIÓN EN ESPAÑA
}

Yolanda Romano Martín (ORCID:0000-0001-6334-9048)

Universidad de Salamanca

\section{La mujer en el fumetto italiano}

En la larga historia del cómic la presencia de la mujer ha ido evolucionando en función de los propios cambios de la sociedad. La discriminación sufrida en otros campos de las artes aquí también se ha evidenciado de manera clara. Con el paso de los años se ha ido despojando de ese papel de mera damisela en apuros o de compañera florero del protagonista. El punto de inflexión fue el nacimiento de las super heroínas de Marvel que han logrado que extendieran los personajes femeninos independientes y con garra.

El mundo de las viñetas ha sido un medio eficaz para expresar sus discrepancias con la sociedad que le ha tocado vivir. De las viñetas en que la mujer ejercía roles estereotipados y machistas a hoy el camino ha sido largo. En la actualidad se ha logrado trasmitir la imagen de una mujer moderna, autónoma y empoderada, aunque conviva con la imagen erotizada e hipersexualizada de algunos personajes femeninos.

El fumetto italiano que nos ha regalado muchos y grandes personajes masculinos, también nos ha hecho llegar a sus mujeres de papel como protagonistas de sagas de éxito o como personajes secundarios. Un abanico amplio para un público de lectores variado que desde el hombre adulto, al adolescente en proceso de maduración, pasando por las mujeres.

\subsection{Las pioneras en el cómic de aventuras en los años 40-50}

Los primeros personajes femeninos italianos que se conocieron en España se remontan a finales de los 40 . Tras el éxito del cómic de aventuras con personajes importados de Estados Unidos y personajes autóctonos, las viñetas italianas se vuelven más picantes con 
“Transfer” XV: 1-2 (2020), pp. 412-433. ISSN: 1886-554

la aparición de las mujeres como protagonistas. Los primeros en apostar por mostrar el cuerpo de la mujer para afirmar su personalidad fueron Gian Giacomo Dalmasso y Enzo Magni quienes crearon a Pantera Rubia y a Gacela Blanca.

La Pantera rubia: la reina de la jungla italiana.

Fue la protagonista de una serie publicada por A.R.C. de Pasquale Giurleo entre 1948 y 1950. Los 108 números que se editaron alcanzaron un notable éxito de ventas, más de 100 mil copias, un verdadero récord para el mercado italiano de la posguerra. Esta imitadora de la americana Sheena ${ }^{1}$ fue un personaje muy controvertido por su minúsculo vestuario, su comportamiento agresivo y por luchar de tú a tú contra los hombres. Su sexy mini bikini de leopardo y sus acciones violentas no eran del agrado de la sociedad tradicional de la época. Esta mujer se había criado con una vieja china llamada Fior di Loto y con Tao, un chimpancé. En sus aventuras tenía que vérselas con los soldados japoneses sus mayores enemigos. A pesar de su imagen rompedora, al final de la serie nuestra protagonista sucumbe al amor tradicional y se casa con Fred. Este cóctel de ingredientes hizo que la editorial tuviera muchos problemas y su dueño procesado por ello. Fue precursora del cómic erótico en Italia que triunfaría algunos años más tarde. Ha sido considerada una verdadera feminista usando todas sus armas, incluida la violencia, para lograr sus objetivos. Esta bella mujer no necesitaba ser protegida por un hombre, pero no le hacía ascos a tener uno cerca. La osadía de su dibujante provocó que el editor sufriera los recortes de la censura obligándoles a retocar la vestimenta del personaje, lo que supuso un importante descenso en las ventas. Llegó a España con el nombre de Pantera rubia y se dio a conocer en 1949 en la editorial Hispano Americana. Para superar la censura española, aquí vestía una blusa y una falda larga hasta la rodilla de piel felina. 45 números y uno extra, todos

\footnotetext{
${ }^{1}$ Sheena era un personaje creado en 1937 por Samuel Maxwell Iger y Will Eisner. La serie de historietas duró hasta el año 53.
} 
“Transfer” XV: 1-2 (2020), pp. 412-433. ISSN: 1886-554

ellos ediciones censuradas y retocadas se publicaron en la serie $\mathrm{La}$ selva. En los años 80 Comic-Mam realizó una reedición facsimilar. Gacela blanca: la sexy princesa india.

De la misma editorial y de los mismos autores Gian Giacomo Dalmasso, Enzo Magni y Carlo Savi es Aquila Bianca la princesa de la tribu de los Castores quien lucha junto a Erwo, el perro Lip y el cazador Rugby para mantener la paz entre los pieles rojas y los blancos. Nuestra heroína protagonizó 28 historias todas ellas en 1949. En España la serie se tradujo con el nombre Gacela blanca y la misma editorial Hispano americana fue quien publicó 54 números entre 1949 y 1951. También sufrió un cambio en su vestuario puesto que su falda se alargó por debajo de la rodilla.

\subsection{Las mujeres del cómic negro en los años 60: Eva Kant y Satanik}

Siguiendo esta línea de mujeres de cuerpos superatractivos, las hermanas Giussani nos regalaron un personaje lleno de carisma: Eva Kant o Lady Eva Kant la co-protagonista del mítico cómic Diabolik, el criminal más longevo de la historieta italiana. Diabolik de negro y siniestro, Eva rubia y sensual, representaban en dúo perfecto donde la complicidad era su fuerza. La compañera del rey del terror aparece por vez primera en 1963 en L'arresto di Diabolik. Su nacimiento supone toda una novedad para la época porque venía a completar la personalidad de su alter ego masculino. Esta vez Eva no actúa como una mera espectadora, sino que ejerce una función específica y activa como cómplice. Toma su nombre del apellido de Emmanuel Kant admirado desde la adolescencia por Angela Giussani. Por su belleza y su feminidad representa un modelo de estilo de mujer imitado en otros campos como la moda o la publicidad. En España apareció inicialmente de manera esporádica en la revista Macabro entre 1974 y 1976. En 1978 la editorial Nueva Frontera dio a conocer 18 números en una serie titulada Colección Diabolik. En 1987 GTS Grupo Editorial publicó 5 números que sacó con viñetas mutiladas y remontadas y con una traducción deficiente. 
“Transfer” XV: 1-2 (2020), pp. 412-433. ISSN: 1886-554

A Eva Kant y a Diabolik le siguieron una serie de imitadores de menor calidad como Sadik, Infernal, Demoniak, Spettrus, Makabar, Demoniak cuyo ingrediente principal era la violencia en estado puro. De entre todos ellos merece la pena destacar a Satanik por aportar novedades importantes al género. En 1964 de la colaboración de Luciano Secchi (conocido como Max Bunker) y Roberto Raviola (conocido como Magnus) nace Satanik, la princesa de las tinieblas. La novedad residía en que este personaje negativo y malvado era una mujer con una doble vida puesto que Marny Bannister, de día era horrenda y despreciada, y de noche se convertía en exuberante y dominadora. Otra innovación que se introdujo era la incursión de lo sobrenatural, los vampiros y los espíritus del mal. En 1972 Seusa Sociedad Editora Uruguaya sacó en español 24 libros de historietas de esta saga.

\subsection{Jacula, Zora, Yra, Sukia el filón de las vampiras eróticas de los años 70-80}

Tras estos personajes del cómic negro italiano comienza una progresiva permisividad, en cuanto al tema del sexo en la sociedad italiana, que se va a reflejar en el mundo de las viñetas rozando los límites de la obscenidad. Lo que en los 60 habría causado un escándalo ahora en los 70-80 ya no levanta ningún revuelo. Surgen así una serie de personajes más desinhibidos y violentos. La editorial Edifumetto ${ }^{2}$ fundada por Renzo Barbieri, uno de los iniciadores del cómic erótico pornográfico, creó un abanico de mujeres que se alejaba de los cánones. La primera de ellas es Jacula personaje que nace a finales de los 60 y desaparece en 1982. Era una vampira que vivía aventuras en una ambientación cargada de los elementos más característicos del misterio: brujas, maldiciones, castillos encantados, espectros, tumbas etc. Se codeaba con personajes míticos del género del horror como Frankenstein, Jack el destripador o la momia. La gran importancia de este personaje radicaba en que llegó a ser la abanderada de unos

\footnotetext{
${ }^{2}$ Edifumetto dio a conocer otros peculiares personajes femeninos con un marcado carácter erótico: Misteria, Ulula la mujer lobo, Naga la maga o Texana todas ellas conocidas en España por su traducción en diversas revistas.
} 
“Transfer” XV: 1-2 (2020), pp. 412-433. ISSN: 1886-554

valores feministas revolucionarios. Su inesperado éxito fue interpretado como una victoria de la emancipación femenina al identificar en su desinhibición y su coraje, unos valores a los que las mujeres aspiraban lograr algún día. En España se dio a conocer en la serie de 36 libros titulada Zara la reina de los vampiros que publicó Ediciones Elviberia desde 1976.

Una secuela de la icónica vampira Jacula es Zora, un personaje ideado por Renzo Barbieri y Giuseppe Pederiali, que protagoniza una saga longeva, entre 1972 y 1985, con 288 números, editada por Edifumetto Esta atractiva vampira es la hija del profesor Pabst quien en un viaje a Transilvania encuentra el cadáver del conde Drácula. Su hija lo resucita de manera involuntaria y tras ser mordida por él, se convierte en vampira. Sin embargo, ella puede sobrevivir a la luz del sol y luchar contra el malvado conde. Sus aventuras erótico vampíricas se publicaron en español, en varias cabeceras de la Editorial Zinco: Hembras Peligrosas, Misteria, Horror y Monsters. Tuvo también su propia serie titulada Zora la Vampira. La protagonista recordaba físicamente a la actriz francesa Catherine Denueve.

Pertenecientes también a este sello italiano son Yra la vampira creada por Leone Frollo que llega en español en 1981 en la revista Odeon y Sukia, ${ }^{3}$ personaje creado por Renzo Barbieri y Nicola del Principe, una vampira inspirada físicamente en Ornella Muti, que protagonizó también aventuras de carácter erótico y de horror. Originariamente se publicaron 153 números entre 1977 y 1986. En español la colección empezó a dar a conocer en ediciones Zinco del $n^{0} 1$ al $n^{0} 78$ ) para continuar siendo publicada por EDICOMIC (del $n^{0} 79$ a $\left.n^{0} 101\right)$.

\subsection{Valentina Rosselli: la fotógrafa sensual de Guido Crepax}

Tras el filón de mujeres aventureras, fantásticas y vampíricas en las que poco había de mujer real, nos acercamos a uno de los

\footnotetext{
${ }^{3}$ Cómic dedicado a Sukia McNouugh, una vampira descendiente del Conde Drácula de Transilvania. Sukia falleció en el siglo XIII, pero renace en el año 1724 y se traslada a vivir a Nueva York. Debido a un bebedizo, consigue vivir a plena luz del día en busca de sangre y hombres a quienes desposar y acabar con ellos.
} 
“Transfer” XV: 1-2 (2020), pp. 412-433. ISSN: 1886-554

personajes más queridos y míticos en la historia del cómic mundial. Valentina Rosselli, de personaje secundario en la serie Neutron creada por Guido Crepax en 1965, se convierte pocos años después, en la protagonista de su propia saga, debido a su potencial erótico y a que lanzaba una atenta y realista mirada hacia la sociedad y la cotidianidad de su época. Guido Crepax se inspiró en el mundo del cine, del que trató de copiar muchos de los artificios de su lenguaje, y en las historias oníricas de H. P. Lovecraft, perfiló asimismo para la fotógrafa milanesa, una personalidad atractiva y un físico espectacular. Le proporcionó carnet de identidad, por lo que nace el 25 de diciembre de 1942 y muere en 1995 en la última página de la historia Al diavolo Valentina! con 58 años. Esta heroína del cómic, independiente pero frágil a la vez, con armas tan efectivas como unas ligas y botas militares (compitiendo con la francesa Barbarella) fue sin duda el mito erótico de varias generaciones. A nuestro país llegó en 1977 con una recopilación de sus primeras aventuras publicadas por Lumen titulada Valentina. La vida de Valentina en España concluyó en el año 1985 con la entrega Diario de Valentina. ${ }^{4}$

\subsection{Una soñadora maliciosa: Little Ego (1984) de Vittorio Giardino}

Ya adentrados en los 80 hacen su aparición personajes con una mayor complejidad de personalidad. Little Ego que comienza en 1984 en el número 12 de Glamour International Magazine era una serie de historias de carácter erótico y fantástico, y con una gran carga onírica protagonizadas por una mujer peculiar llamada Ego. Cuyo autor y dibujante fue Vittorio Giardino. Con ella realiza un homenaje paródico al personaje Little Nemo creado por el estadounidense Winsor McCay en 1906. Todas las tramas se desarrollan en sus sueños eróticos y surrealistas y concluyen con un brusco despertar. En España esta maliciosa soñadora obsesionada con sus

\footnotetext{
${ }^{4}$ De este autor en nuestro país se darán a conocer, a través de diferentes como Distrinovel, Nueva Frontera o Ediciones Obelisco, aventuras protagonizadas por otras bellas heroínas como Belinda, Bianca, Anita, Emmanuel o Justine (algunas en catalán y vasco).
} 
“Transfer” XV: 1-2 (2020), pp. 412-433. ISSN: 1886-554

fantasías eróticas apareció en aquellos mismos años en la publicación Cimoc de la editorial Norma. Merece la pena destacar el número especial publicado en 1986 dedicado al comic erótico Címoc. Especial. Erotismo y glamour donde aparecieron algunas de sus aventuras.

\subsection{Una heroína sensual en un mundo apocalíptico: Drunna (1984), de Paolo Eleuteri Serpieri}

La ciencia ficción va ganando la batalla a la realidad y acapara el mercado de lectores. Siempre en los 80 nace Druuna, un personaje inspirado en Valerie Kaprinski en la película Femme Publique de Andrzej Zulawski de 1984. Fue creado por Paolo Eleuteri Serpieri quien la presentó primero en la revista francesa Charlie Mensuel en 1985 y después en Pilote (Dargaud). En Italia apareció unos meses después en el $n^{0} 42$ de L'Eternauta. Su nombre es el resultado de la unión de dos palabras bruna, luna y druida (morena, luna y druida). Esta mujer morena de belleza primitiva y salvaje, de piel oscura, labios carnosos, curvas explosivas es la esposa de un mutante. Vive en un mundo post apocalíptico poblado por mutantes y terribles criaturas que la llevan a situaciones límite. Sus historias, cargadas de violencia, de ostentación de la sexualidad y perversión, se publicaron hasta el año 2003 en 10 volúmenes. La primera y más conocida es Morbus Gravis. Esta serie de historias fueron publicadas inicialmente en la revista Zona 84 de Toutain (incluidos los dos primeros recopilatorios). Posteriormente, Norma Editorial se ocupó del resto de la serie y reeditó también los dos primeros números.

\subsection{La Bionda: estafadora y ladrona de Franco Saudelli}

A finales de los 80 el dibujante Franco Saudelli, famoso por sus series de género erótico y de aventuras nos trae a España su serie más longeva protagonizada por La Bionda, una ladrona y estafadora que vive mil aventuras erótico humorísticas en un mundo futurible, donde los coches vuelan. Esta atractiva rubia de cuerpo exuberante tenía los rasgos de la actriz Kathleen Turner, llevaba un pequeño antifaz negro que le cubría los ojos y le proporcionaba un halo de misterio, unos pantalones ajustados y un suje- 
“Transfer” XV: 1-2 (2020), pp. 412-433. ISSN: 1886-554

tador a la vista. La primera serie se publicó entre 1987 y 1991 en la revista Comic Art. Desde 1994 la segunda serie pasó a la editorial Granata Press donde salieron un total de 11 volúmenes mensuales en tamaño de bolsillo. En el año 2000 Saudelli hizo un remake de la primera historia titulada La bionda, Colpo doppio: la storia mai vista en la editorial Glittering Images. En español apareció en diversas publicaciones: en varios números de las revistas Cimoc (1981) y Colección BN (1985), ambas de la editorial Norma y las revistas Totem el Comix (1986) y Sexperiencias (1988), ambas de Toutain Editor.

\subsection{Milo Manara el mito del erotismo en viñetas}

Cuando hablamos de Milo Manara estamos hablando del más importante dibujante de mujeres en la historia del cómic mundial. A pesar de que no todas sus obras tienen carácter erótico se encuadra en este género. Sus mujeres, Claudia, Angelina, Miele, etc., son conscientes de su propia belleza y de sus deseos que controlan y manejan, como manejan también su vida profesional. Dibuja a la mujer de una manera idealizada y personal en ambientaciones oníricas y eróticas, pero representando acciones públicas. Su carrera, en 1969, está ligada a la editorial ErreGI especializada en el cómic de género erótico para la que dibuja a la corsaria Jolanda de Almavida no obstante, el espaldarazo definitivo le llega con Il gioco, su obra más famosa, que publica en Playmen en 1982. Se convierte gracias a obras como El clic (1984), HP e Giuseppe Bergman (1978) y Il profumo dell'invisibile (1985) en el maestro indiscutible del género erótico. Concordamos con el crítico Vincenzo Mollica en su artículo Mondomanara en que el objetivo de las historias de Manara fue el de demostrar que el erotismo era sinónimo de libertad y mejor aún si iba acompañado de amor. Quizás el único defecto de su obra ha sido el no haber renovado el aspecto de sus mujeres, puesto que todas se parecen a su musa Miele, una Kim Basinger subida de tono. Desde 1977 a hoy son muchas las obras en español de Manara resultando imposible hacer referencia a todas ellas puesto que se han repartido por diferentes editoriales como: Activities K (El clic, El perfume del invisible, El pintor y la modelo, Los ojos de Pandora), Norma Edi- 
“Transfer” XV: 1-2 (2020), pp. 412-433. ISSN: 1886-554

torial (Verano indio, Tal vez soñar, Venus y Salomé, El Gaucho, Desnuda por la ciudad, Gulliveriana, Kamasutra, Las mujeres de Manara, Cámara indiscreta, El perfume del invisible, Kamaslitra); la desaparecida editorial New comic (El rey mono, Candid camera, Cámara indiscreta, Viaje a Tulum, Cuentos fantásticos, Mp y Giuseppe Bergman, El clic).

\subsection{Julia Kendall y las mujeres Bonelli}

La editorial Sergio Bonelli indudablemente ha sido una de las factorías del cómic italiano que más personajes y sagas de éxito ha proporcionado al público italiano, por ello merecen un apartado dedicado a sus féminas. De sus dibujantes e historietistas han salido los personajes más longevos del mundo de la tinta y el papel que forman parte del imaginario colectivo: Tex Willer, Dylan Dog, Zagor, Piccolo Ranger, Magico Vento, Nathan Never o Martin Mystere dominando el mercado del cómic italiano al haber abarcado todos los géneros más populares. La única saga protagonizada por una mujer que llega a España es la de Julia Kendall. Esta criminóloga bella y de extraordinaria sensibilidad es la protagonista de una serie de historias de corte policial muy exitosa. El personaje, ideado por Giancarlo Berardi en 1998, tomaba las facciones de la actriz Audrey Hepburn y surge por la voluntad del editor de tener una nueva serie policial tras la finalización de Ken Parker. El hecho de que esta mujer representara a una mujer normal, sin demasiados artificios, fue un factor determinante y la razón por lo que sus lectoras eran mayoritariamente mujeres y adolescentes. La serie ambientada en una ciudad americana imaginaria donde nuestra criminóloga vivía con su gato y trataba de resolver los enigmas y misterios que se le presentaban acompañada del teniente Alan J. Webb y del investigador privado Leonard "Leo" Baxter. Las historias de esta fascinante investigadora se han publicado de manera ininterrumpida desde su creación hasta hoy y en nuestro país gracias a Aleta Ediciones hemos podido leer en español 12 volúmenes empezando por la primera historia: Los ojos del abismo, pero sólo a partir del año 2011. 
“Transfer” XV: 1-2 (2020), pp. 412-433. ISSN: 1886-554

Del resto de personajes femeninos del sello Bonelli nos han llegado solo los secundarios que han acompañado a algunos de los protagonistas más míticos. Son dignos de mención: Morgana, el verdadero y único amor de Dylan Dog; Sera di Frondascura una joven elfa que combate junto a Dragonero, el protagonista de la saga de fantasía heroica juvenil creado por Luca Enoch como guionista y Giuseppe Matteoni como dibujante; Patricia Rowland la arqueóloga norteamericana compañera de Mister No; Diana Lombard la esposa de Martin Mystère, el investigador de lo imposible y protagonista de una serie de historias de aventuras fantásticas y de ciencia ficción creadas por Alfredo Castelli.

\subsection{Mujeres en un mundo de fantasía y ciencia ficción:}

\section{Sky Doll, End 1, Ekho}

Ya en el siglo XIX el comic se puebla de mujeres de ciencia ficción muy lejanas de las mujeres de carne y hueso.

En un universo ficticio distópico se desarrollan las historias de Sky Doll donde lucha por sobrevivir Noa, una muñeca mecánica que a pesar de no tener derechos y tener que cumplir la voluntad de su dueño, es capaz de soñar y de recordar. Al morir su Dios ella se embarcará en peligrosas misiones. Esta serie ideada en 2000 por Barbara Canepa y Alessandro Barbucci cosechó un gran éxito no solo en su país, sino en Corea, Japón, China, Estados Unidos, Francia y a España llega a gracias a la iniciativa de Norma Editorial que ha publicado entre 2002 y 2019, los cuatro volúmenes de la serie y los álbumes especiales.

Del mismo Alessandro Barbucci, pero esta vez en colaboración con Christophe Arleston, es la serie de ciencia ficción Ekhö: Mundo Espejo. Al igual que la anterior, en estas historias se evidencia el sello de sus autores, por la calidad del dibujo electrizante y una sorprendente fantasía que atrapa al lector. Ekho representa un mundo paralelo a la Tierra con nuestras mismas ciudades, pero ligeramente diferentes. No hay electricidad y los dragones sustituyen a los aviones. Es habitado por los Preshaun, una especie de ardillas humanas, que tienen las riendas de este peculiar mundo. La joven Fourmille Gratule y Yuri Podrov aterrizarán de manera inesperada en Ekho y allí viajarán a las versiones paralelas de 4 
“Transfer” XV: 1-2 (2020), pp. 412-433. ISSN: 1886-554

ciudades: Nueva York, París, Hollywood y Barcelona. Este interesante e imaginativa serie de cómics, a la que no le falta un toque humorístico; en esta visión dicotómica de la realidad, se muestra una crítica a nuestra sociedad actual, ridiculizando sus vicios y defectos. Desde 2014 a 2019 Norma editorial se ha encargado de dar a conocer la saga publicando 8 álbumes.

End 1. Elisabeth es un libro de cómic creado por Barbara Canepa en colaboración con Anna Merli en 2012, que Norma Editorial ha publicado recientemente. En esta primera trama nos encontramos con una inquietante y joven protagonista de 13 años llamada Elisabeth en un mundo inanimado, sin color donde las almas y los espíritus parecen hallar la tranquilidad de la eternidad.

\subsection{Un personaje histórico: Marina de Matteo Alemanno y Zidrou}

En nuestro periplo por la historia de las mujeres del cómic no podían faltar los personajes históricos. Marina es el personaje protagonista de la saga creada por Zidrou y por Matteo Alemanno un reconocido dibujante italiano que inicia su carrera en los años 90 en la revista Schizzo, idee e immagini de Cremona. La protagonista Marina Dandolo (la pantera) es la hija del Dux de Venecia Andrea Dandolo que gobernó a mediados de 1300 . La joven y su hermano Giovanni Zuane se ven envueltos en diversos conflictos diplomáticos entre Venecia y el Imperio Turco. Las historias se desarrollan en dos líneas temporales alejadas el presente y el siglo XIV. Encontramos fidelidad a los acontecimientos históricos, ficción, intrigas políticas, misterios y profecías y como resultado, un atractivo fresco de la época. Entre 2014 y 2017, gracias a la editorial barcelonesa Norma contamos con 3 números en español: Los hijos del Dux, La profecía de Dante Alighieri y ¡Razzias!

1.12. Las nuevas heroínas de las adolescentes: Las W.I.T.C.H. y las Winx Club: amigas con superpoderes

La serie ideada en 2001 por Elisabetta Gnone, en colaboración con Alessandro Barbucci y Barbara Canepa significaba la primera incursión de la Disney Italiana en el mundo del cómic para chicas. Las W.I.T.C.H. eran cinco jóvenes adolescentes, Will Vandom, Irma 
“Transfer” XV: 1-2 (2020), pp. 412-433. ISSN: 1886-554

Lair, Taranee Cook, Cornelia Hale y Hay Lin Lin que descubren tener un poder mágico basado en los cuatro elementos de la naturaleza por ello deciden luchar contra el mal convirtiéndose en las Guardianas de Kandrakar con la misión de proteger la muralla. A pesar de que el nombre en inglés significa bruja en realidad es el acrónimo formado por las iniciales de sus nombres. Las cinco jóvenes de 13 y 14 años representaban los valores de la amistad y el trabajo en equipo. Eran una interesante metáfora sobre los cambios que experimentan las adolescentes. Las amigas debían en cada una de sus aventuras luchar para mantener la paz y la harmonía en el universo. Lo atractivo de la serie radicaba seguramente en la interpretación mágica de lo cotidiano. Inicialmente se pensó en lanzar solo 12 volúmenes, pero debido al estrepitoso boom de lectores, se siguieron publicando hasta el 2011 llegando a vender, en sus picos más altos, 250.000 ejemplares al mes. A lo largo de los años en que estuvo a la venta se realizaron 139 revistas.

El éxito traspasó las fronteras italianas y se extendió a más de 28 países de Europa y del mundo, como un auténtico fenómeno global. En España salió una colección de 20 libros de historieta de 192 páginas en color, más cubiertas en cartoné, en la que se recopilaba la totalidad de la serie previamente publicada por Walt Disney Iberia en revistas, a razón de tres episodios originales por libro. Durante varios años la revista lideró las ventas en España de cómics para adolescentes y alcanzó una cuota de más del $11 \%$ de su público objetivo de niñas entre los 9 y 14 años.

En 2004 Iginio Straffi, fundador de Rainbow, da vida a las Winx Club, una supuesta copia de las anteriores por lo que tuvo que ir a juicio para defender su originalidad. El juez no sólo determinó que no eran un plagio, sino que dictaminó que eran más originales que las anteriores. Las Winx eran, Blomm, Stella, Flora, Layla, Musa y Tecna, 6 hadas adolescentes, con mucho estilo y un don particular para la magia. Sus historias están ambientadas en el mundo mágico de Magix poblado por brujas, monstruos, humanoides y hadas. Sus historias fueron llevadas a televisión y al cine y se exportaron a muchos países, convirtiéndose en todo un fenómeno, hasta el punto de vender más muñecas inspiradas en 
“Transfer” XV: 1-2 (2020), pp. 412-433. ISSN: 1886-554

sus personajes que la propia Barbie. En España salieron 5 temporadas de las 8 que conforman la saga, y dos películas de la serie.

\section{Mujeres que dibujan mujeres}

No queríamos concluir este recorrido por las mujeres en el cómic italiano sin presentar una breve panorámica de las guionistas y dibujantes italianas más relevantes que se conocen en nuestro país, desde diferentes perspectivas y géneros.

\subsection{La reivindicación feminista desde el humor, o cómo reírse de sí mismas: Silvia Ziche y Pat Carra}

Nos encontramos en pleno empoderamiento de la mujer en todos los campos y el cómic no podía ser menos. A pesar de no conocer aún en español a autoras como Nicoz, Deco, Ellekappa, Cristina Fabris, Cinzia Leone o Laura Scarpa sí podemos nombrar tomar el pulso con las autoras que proponemos a continuación.

Silvia Ziche es una escritora y dibujante italiana que ha desarrollado parte de su carrera profesional vinculada a los cómics de Disney en Italia, especialmente en la revista semanal Topolino; además ha trabajado para las revistas Linus, Comix, Cuore o Donna Moderna, donde publica las historias de Lucrezia. Este personaje fetiche es una treintañera, soltera inteligente que sueña encontrar un día a su príncipe azul. En esta búsqueda tiene ocasión de conocer a una vasta tipología de hombres: el inseguro, el demasiado meloso, el matemático, el machista, el artista incomprendido, el amigo enamorado, etc., hasta que logra alcanzar al hombre ideal que resulta ser demasiado perfecto $y$, a la postre aburrido. ...Y nosotras, ¿dónde estábamos? (2019), publicada por la editorial Akal, es la única obra que en España se ha traducido de Ziche protagonizada por Lucrezia cuyo título original en italiano es E noi dove eravamo (2018). Es una novela gráfica divertida, amarga y surrealista sobre el papel de las mujeres en la historia de la humanidad. Nos descubre a interesantes mujeres que desgraciadamente han permanecido al margen de los libros de historia. En un riguroso trabajo de investigación, pero al que no le 
“Transfer” XV: 1-2 (2020), pp. 412-433. ISSN: 1886-554

falta un tono irónico y divertido Ziche trata de reivindicar y poner en valor a figuras femeninas superando lugares comunes y prejuicios de género.

Nuestra segunda autora que domina el mundo del humor, la política y el feminismo es Pat Carra. Se inicia en el cómic en los años 70 gracias a la Libreria delle donne de Milán, con quienes dirige y funda la revista humorística Aspirina. Rivista acetilsatirica. Esta librería nace en 1975 con la intención de hacerse eco de la realidad política en continuo cambio. Por iniciativa de la librería se publican dos revistas trimestrales Via Dogana (desde 1991) y Aspirina. Rivista acetilsatirica (desde 1987 a 2018). En la actualidad la revista Aspirina ha cambiado su nombre por el de Erbacce. Forme di vita resistenti ai diserbanti. Ha colaborado y lo sigue haciendo en la actualidad en revistas y periódicos italianos y extranjeros como Smemoranda, Cuore, Donna Moderna, Donna e mamma, Noi donne, Corriere della sera, Il Manifesto, Ego (Grecia), Luna (Argentina). Con un estilo y un trazo muy sencillo, la autora presenta a la mujer en diferentes facetas de la vida, en familia, en el trabajo o en la sociedad. Son siempre personajes anónimos, sin nombre porque en cierto modo representan a cualquier mujer de hoy. Ha publicado diversos volúmenes siempre protagonizados por mujeres como Donne moderne (1992), La Signora Pontida (1994), Svegliatevi bambine (1996), Orizzonti di boria (1999), Cassandra che ride (2004), La mani sulla casa. Fatti e fumetti sulla bolla immobiliare (2007), Annunci di lavoro (2010), Sex of humour (2011), Annunci a luci rosse (2014) y Nuvole basse (2016).

Pat Carra es sin duda una de las dibujantes de culto por su lucha por derribar estereotipos, sobre todo los relacionados con la sexualidad y hacerlo desde un punto de vista humorístico. En los últimos años ha realizado diversas exposiciones donde mezcla el mundo de las viñetas con otras formas artísticas, con materiales muy diversos desde el lino, la cuerda, el algodón africano, los botones de madreperla indios o la yuta. En España gracias a la labor de la Librería Mujeres y su editorial Horas y horas se conoce una pequeña parte de su reivindicativa obra. Además, ha colabora- 
“Transfer” XV: 1-2 (2020), pp. 412-433. ISSN: 1886-554

do y lo siguen haciendo en diversas publicaciones: la revista Clara, la revista feminista DUODA. Estudios de la diferencia sexual ${ }^{5}$ editada por la Universidad de Barcelona. En 1999, Pat Carra publicaba Orizzonti di Boria (Quaderni di Via Dogana) donde se recogía las viñetas satíricas de Pat que comentaban la guerra de los Balcanes. Muchos de los dibujos contenidos en aquel libro sirvieron para ilustrar Guerre che ho visto cuyas autoras eran intelectuales relevantes como Luisa Muraro, Clara Jourdan, Ida Dominijanni, Virginia Woolf, Chiara Zamboni, Annarosa Buttarelli, Delfina Lusiardi y Weil que aportaban sus reflexiones en torno al sistema patriarcal y al belicismo. En 2001 apareció un doble volumen en el que se incluía por un lado la traducción al castellano Guerras que yo he visto: saberes de mujeres en la guerra en la (editorial Horas y Horas, Cuadernos inacabados. Madrid, 2001) y por otro una recopilación de viñetas antibelicistas de Pat Carra titulada Bombas de risa ${ }^{6}$, que ilustraban con ironía y humorismo, un tema tan serio como la participación en las guerras. Más reciente es la publicación en español de La bella durmiente hace el turno de noche (2011) Sabina Editorial cuyo título original era $\mathrm{La}$ Bella Addormentata fa il turno di notte (Ediesse 2005): una original visión de la mujer en el mercado del trabajo. Este cómic es un verdadero cuento moderno protagonizado por la Bella Durmiente, Cenicienta, Blancanieves o Caperucita roja que ilustra las dificultades que encuentran en su camino: contratos, despidos, conciliación, relación con los hombres, sus propias contradicciones, etc... Este surrealista cuento nos recuerda el publicado en 2017 por Raquel Córcoles, Moderna de Pueblo titulado Idiotizadas: de cuento de hadas a empoderhadas donde también la popular dibujante española realiza una metáfora del mundo de las princesas y prín-

\footnotetext{
${ }^{5}$ La Revista DUODA, fundada en 1991, publica la escritura femenina de prosistas, poetas y artistas que conocen el misterio de la lengua materna y saben vivir, estudiar, pensar y crear sintiendo el orden simbólico de la madre. En la actualidad está dirigida por Laura Mercader y María Milagros Rivera. Es una revista de periodicidad semestral en la que Pat Carra forma parte del comité de sabias.

${ }^{6}$ La obra se publicó en italiano con el título Cassandra che ride Milán: Baldini Castoldi Dalai, 2004 y constaba de cuatro capítulos: Guerra moderna, Dolor, Muerte y Religión.
} 
“Transfer” XV: 1-2 (2020), pp. 412-433. ISSN: 1886-554

cipes de Disney para denunciar estereotipos de género que sufren las mujeres hoy día.

\subsection{Bambina filosófica de Vanna Vinci: una nueva Mafalda del siglo XXI}

Comienza su carrera en 1990 ilustrando libros infantiles para editoriales como Fabbri, Mondadori o Tam Tam. En la actualidad colabora en la página cultural del periódico L'Unità. Entre sus obras merece la pena destacar la serie dedicada a la Bambina filosófica, una especie de Mafalda de nuestros días, que le ha hecho muy popular entre los lectores más jóvenes. Desde La bambina filosofica. Anatomia di uno sfacelo publicada en 2004 en Kappa edizioni Jet Lag hasta el momento han salido varias historias de esta niña enamorada de las nuevas tecnologías: La bambina filosofica. Pensieri, parole, opere, omissioni (2006), La bambina filosofica. Pillole di saggezza altrui (2007), La bambina filosofica. Pape Satàn aleppe (2008), La bambina filosofica. Houston, abbiamo un problema (2012) y La bambina filosofica. L'opera (quasi) omnia (2013). Su única obra perteneciente a la serie en España es $\mathrm{La}$ bambina filosófica: Anatomía de una ruina publica en 2011 por la editorial Planeta y su edición en catalán: La bambina filosófica: Anatomía d'un fracàs editado por Estrella Polar. Esta jovencita puede llegar a ser un nuevo icono post-pop, propio de la sociedad en la que vivimos pues habla como una chica de treinta y tantos años, culta, sarcástica e irónica. Su madre ha pensado en darla en adopción, tiene un peluche seguidor de Nietzsche, que es su confesor; y vive con un cerdito que es un ideal de virtud y de orden. Su contrapunto Angélica, su compañera de clase.

\subsection{Valentina y Stefi dos encantadoras adolescentes de Grazia Nidasio}

Esta dibujante e historietista, recientemente fallecida, ha sido una de las artistas más sobresalientes del cómic italiano. Tras estudiar escultura, a finales de los cincuenta e inicios de los sesenta, conoce al gran ilustrador Giorgio de Gaspari y gracias a él y a su hermana Gigliola que escribe libros para niños, se acerca al mundo de la ilustración. Comienza a trabajar el Il Corriere dei Piccoli, don- 
“Transfer” XV: 1-2 (2020), pp. 412-433. ISSN: 1886-554

de ilustra numerosas series, como Violante Rock, Niccoletta, Signorina Vanità, etc. En 1969 comienza una historieta protagoni-zada por Valentina Mela Verde, su personaje más famoso que debuta en las páginas de Il Corriere dei Piccoli y continuará en Il Corriere dei Ragazzi hasta 1976. Valentina, llamada Mela Verde, es una simpática preadolescente de 11 años pelirroja de ojos azules que vive en Milán con su familia y que como en un diario nos cuenta sus impresiones sobre todo lo que le pasa. Las historias de esta jovencita enganchan enseguida a un numeroso público de lectores que esperaban ansiosos la entrega semanal de una nueva aventura. Ha sido una de las novelas gráficas más logradas de la historia del cómic italiano, fiel reflejo de la Italia de los años 70. Poco a poco la hermana pequeña de Valentina, Stefi de 8 años, va adquiriendo más espacio y le roba todo el protagonismo. Esto ocurre en 1972 cuando Il Corriere dei Piccoli se desdobla en Il Corriere dei Ragazzi para acaparar un mayor número de lectores. Las aventuras de esta niña inconformista siguen durante los 80 y los 90 pero no concluyen con el cierre de la revista en 1995. En 1976, Nidasio crea una nueva serie, protagonizada por Stefi, en formato de diario personal, que logra adquirir fama internacional. En España las hermanas Morandini se dieron a conocer a través de las publicaciones infantiles y juveniles más populares de aquellos años. Primero aparece en 1978 en la revista de historietas GINA, del sello Editorial Bruguera. A partir del año 1981 se publican también en la revista de historietas ESTHER, del sello Editorial Bruguera. Su hermana pequeña Stefi, fue un caso curioso dado que tuvo en España diferentes nombres tanto la serie como el personaje. En 1987 aparece con el nombre de Estefi en la publicación infantil catalana CAVALL FORT del sello editorial Secretariats catequístics de Girona, Vic I Solsona, Fundació Cavall Fort. En el número 600 con guión y dibujos de Grazia Nidasio y adaptado por Alber Jané aparece El diario d'Estefi. Seguirá publicándose en catalán en durante muchos años hasta los números 1009-1010 de agosto de 2004. En la revista ZIPI Y ZAPE de la editorial Bruguera, en su número 347 del año 1979, se publica una historieta completa titulada El Diario de Lita por lo tanto pasa a llamarse Lita en castellano. Con posterioridad El pequeño País de ediciones El País, 
“Transfer” XV: 1-2 (2020), pp. 412-433. ISSN: 1886-554

desde 1996 a 1998, publica diversas historias, pero esta vez se llamará Nina.

\subsection{La novela gráfica de Barbara Baldi, Simona Mogavino}

Barbara Baldi es una importante ilustradora y dibujante italiana que trabaja para numerosas editoriales como Pixar, Disney, Marvel, Eli Edizioni, De Agostini, Piemme, Il Battello a Vapore, Norma Editorial, Glénat Québeq. Se formó en la Academia Disney de Milán y desde entonces ha colaborado en diferentes series de cómics populares como Sky Doll, Monster Allergy o Will. También ha realizado las ilustraciones de la serie de libros para adolescentes Fairy Oak de Elisabetta Gnone. Tras esta etapa como ilustradora en 2017 se lanza al mundo de la novela gráfica porque quería ampliar horizontes. Elige una editorial desconocida, Oblomov Edizioni para publicar Lucenera un magnífico drama romántico ambientado en el condado de Nottinghamshire en la Inglaterra de 1850. Esta novela cuenta la historia de dos hermanas enfrentadas por una herencia quienes, tras la pérdida de su abuela, ven cómo sus destinos se separan por voluntad ajena. Clara es la protagonista, una mujer pelirroja que debe superar el abandono y la soledad impuesta. Baldi utiliza la técnica digital y la acuarela para dar vida a unas imágenes muy cercanas al expresionismo y al impresionismo, de una belleza extraordinaria. Muchas de las viñetas parecen obras de Monet, Vermeer o de Friedrich, en un evidente homenaje al mundo del arte. La segunda novela gráfica es Ada una historia con tintes autobiográficos, definida por ella misma como un drama crudo y sin filtros. Ada es una joven incomprendida, maltratada por su padre autoritario e ignorante que desprecia su talento artístico. Con la ayuda de un compañero del instituto logrará desarrollar este don por la pintura que significará un verdadero camino de empoderamiento. Su primera exitosa novela gráfica ha sido traducida y publicada en 2019 por la editorial Norma en España con el título Mala Estrella.

Por su parte, Simona Mogavino después de una larga carrera como restauradora de arte en 2012, decide abandonar esta actividad por problemas de salud y dedicarse al mundo de las viñetas como guionista. Junto al ilustrador argentino Carlos E. 
“Transfer” XV: 1-2 (2020), pp. 412-433. ISSN: 1886-554

Gómez y el guionista francés Arnaud Delalande debuta con la publicación en Francia de una novela gráfica de corte histórico, Alienor la legende noire que le permite alcanzar una gran popularidad y comenzar una serie de novelas dedicada a las reinas de sangre. En España la editorial barcelonesa Yermo ediciones ha publicado tres libros de la saga Las Reinas de sangre. En 2014, dos volúmenes de Isabel. La loba de Francia y un volumen dedicado a Leonor La leyenda negra y un último volumen titulado Cleopatra. Estas historias reales ficcionadas por la autora, nacen de su pasión por estos personajes femeninos históricos de fuerte personalidad.

\subsection{Giovanna Casotto: la reina del cómic erótico del siglo XXI}

Volvemos al erotismo y la exhibición de la imagen femenina con una mujer que dibuja cuerpos de mujeres. Giovanna Casotto llega al mundo de la tinta y el papel por casualidad. La afición de su marido por los cómics eróticos despierta en ella un inesperado deseo de dibujar a mujeres como aquellas. Tras divorciarse de su marido, las viñetas se convierten en su terapia y durante tres años asiste a la Scuola del Fumetto de Milán para formarse. En 1994 conoce al ilustrador Franco Saudelli que pasa a ser su mentor y con el que inicia una relación profesional y sentimental. Se consolida como dibujante a la vez que posa como modelo para Saudelli. Ambos firman varios trabajos juntos en distintas publicaciones. Destacan sus numerosas colaboraciones en revistas eróticas: las italianas Selen y Blue, la británica Desire, Eros Comix y Penthouse en USA, Tegnesex en Dinamarca, Collection $X$ en Alemania, Coleção Eros en Brasil o la española Kiss Comix. Aunque el panorama de las mujeres en el cómic erótico italiano se ha ido ampliando en estos últimos años con figuras como Cristina Fabris, Serena Paccagnani o Vanessa Santato, Giovanna Casotto es la más famosa en absoluto. El erotismo de desprenden sus dibujos está inspirado en los años 50, época por la que siente fascinación. Por ello sus modelos de mujer son la pin up Bettie Page o las divas de Hollywood Lauren Bacall y Audrey Hepburn. Utiliza para ello el blanco y negro con detalles en color en los elementos más fetichistas: zapatos de tacón, ligas, ropa interior, etc. Su erotismo, lleno de ironía e ingenua malicia, pretende poner de relieve la sensualidad de la mujer. 
“Transfer” XV: 1-2 (2020), pp. 412-433. ISSN: 1886-554

Entre los guionistas de sus ilustraciones destacan Franco Saudelli, Lillo, Fernando Caretta, Diego Cajelli, Mauro Muroni, Massimo Zanichelli, Alessio Schreiner y Flavio D’Atri. En España sus ilustraciones comienzan a conocerse a través de la revista Colección X y en la publicación periódica Kiss Comix ambas de Ediciones La Cúpula en el año 1997. En el año 2014 se publica su volumen Pin up en 001 Ediciones en el que se recopilan ilustraciones de mujeres de gran calidad con el que pretende sacar del círculo restringido de lectores y galerías especializadas a este género a veces infravalorado.

\subsection{Biografías de mujeres: Marie Curie de Alice Milani}

No queremos terminar este recorrido sin mencionar un tipo de novela gráfica que cuentan vidas de mujeres. Alice Milani es una interesante dibujante e ilustradora, fundadora que un grupo de autoedición de Bolonia. Hasta el momento ha publicado 3 novelas gráficas. La última de ellas en 2017 es la biografía en viñetas de la científica polaca Marie Curie. Con un estilo delicado pero incisiva Milano nos acerca a esta mujer racional y de gran carácter en la que salen a la luz su fragilidad, pero al mismo tiempo su férrea voluntad y pasión por su carrera de investigadora. La vida de esta interesante mujer, todo un ejemplo de superación y determinación, nos llega en viñetas a España en 2019 gracias a la editorial Nórdica.

\section{Conclusiones}

En nuestro recorrido por las mujeres de papel italianas que hemos podido conocer en español nos han quedado y quedan aún muchas por descubrir, sobre todo las más reivindicativas. Una de las razones puede ser el descenso considerable del número de traducciones de historietas italianas que se han publicado en España en los últimos 10 años, que se ha visto ampliamente superado por el cómic americano y el manga japonés. Aunque en ambos países hayan aumentado considerablemente el número de mujeres dibujantes e historietas y personajes femeninos, algunas 
“Transfer” XV: 1-2 (2020), pp. 412-433. ISSN: 1886-554

de éxito, creemos que aún queda mucho camino por recorrer, pero sin duda, merece la pena poner en valor y reconocer su esfuerzo titánico acabar con la desigualdad, la discriminación y la cosificación de la mujer.

\section{Referencias bibliográficas}

AA.VV. (2002). El cómic en España, Ministerio de cultura.

ALOI, Dino. (2011). La donna immaginata, L'immagine della donna. Turín: Edizioni Il pennino.

FERRARI, Paolo \& PRANDI, Mario. (2014). Guida al fumetto italiano. Bolonia: Odoya Edizioni.

GASCA, Luis \& GUBERN, Román (2011). El discurso del cómic. Madrid: Cátedra.

MOLLICA, Vincenzo. (2007), "Mondomanara”. En: MANARA, Milo \& KAMASUTRA, Gulliveriana, "Tre ragazze nella ree", Il Sole 24 Ore, (2007), p. IV.

RESTAINO, Francesco. (2004), Storia del fumetto italiano. Da Yellow Kid ai manga, Turín: UTET.

SMOCOVICH, Mauro \& MARRACCI, Elio. (2008). Dizionoir fumetto. Milán: Delos Books.

Fecha de recepción: 7.10.2019 Fecha de aceptación: 21.10.2019

\section{Resumen:}

Este trabajo pretende mostrar una panorámica de los personajes femeninos de las viñetas italianas que se han conocido en España. Desde sus inicios, la historia del cómic italiano nos ha ofrecido una gran variedad de mujeres de todas las edades y en roles diversos: desde la heroína, la villana, el ama de casa pasando por la damisela inocente, la radical feminista o la bomba sexy. Muchos son los arquetipos que conforman una gran gama de estereotipos 
“Transfer” XV: 1-2 (2020), pp. 412-433. ISSN: 1886-554

femeninos en el mundo del cómic y cada uno de ellos encuentra su explicación en los fundamentos sociológicos y de análisis de la cultura de masas. Veremos de qué manera han ido apareciendo en España y cómo ha sido su recepción entre la crítica y los lectores.

Palabras clave: Cómic, Mujer, Historia del cómic, Feminismo.

\title{
THE EVOLUTION OF THE IMAGE OF WOMEN IN THE ITALIAN COMICS AND ITS RECEPTION IN SPAIN
}

\begin{abstract}
:
The aim of this project is to show an overview of the female characters of the Italian comics that have been published in Spain. Since its inception, the history of Italian fumetti has offered us a wide variety of women of all ages and in different roles: from the heroine, the villainess or the housewife to the innocent damsel, the radical feminist or the sexy bomb. Many are the archetypes that make up a wide range of female stereotypes in the comic world and each of them finds its explanation in the sociological and analytical foundations of mass culture. We will see how they have appeared in Spain and how have been perceived among the critics and readers.
\end{abstract}

Keywords: Comic, Woman, Comic History, Feminism. 